\title{
Analisis karakteristik pirolisis limbah plastik low density polyetylene (LDPE) sebagai bahan bakar alternatif
}

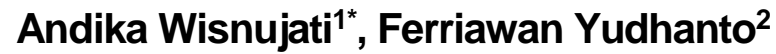 \\ ${ }^{1}$ Program Studi D3 Teknologi Mesin, Universitas Muhammadiyah Yogyakarta \\ Jl. Brawijaya, Tamantirto, Kasihan, Bantul, DIY, Indonesia \\ ²Program Studi D3 Teknologi Mesin, Universitas Muhammadiyah Yogyakarta \\ Jl. Brawijaya, Tamantirto, Kasihan, Bantul, DIY, Indonesia \\ ${ }^{*}$ Corresponding author: andikawisnujati@umy.ac.id
}

\begin{abstract}
Plastic bag waste in Indonesia is very alarming. The many uses of plastic bags and those made from plastic in the food sector, industry, and others will have a bad impact on the environment if it carried out continuously and the utilization of waste plastic bags. This research was conducted by utilizing waste plastic bags Low-Density Polyethylene (LDPE) to be converted into fuel oil by the pyrolysis process. Starting from the design and manufacture of pyrolysis devices, the process of pyrolysis for extracting fuel oil, and laboratory testing of oil density, oil viscosity, and oil calorific value. Pyrolysis was carried out three times with heating temperatures varying at $200^{\circ} \mathrm{C}, 250^{\circ} \mathrm{C}$, and $300^{\circ} \mathrm{C}$. This research concludes that pyrolysis oil of LDPE plastic bag waste that can be used for alternative fuels in this research can be ignited through a spark at a heating temperature of $250^{\circ} \mathrm{C}$ with a viscosity of $1.95 \mathrm{cP}$, a calorific value of $10826.388 \mathrm{cal} / \mathrm{gr}$, and an oil density of $0.7044 \mathrm{gr} / \mathrm{ml}$
\end{abstract}

Keywords: plastic, pyrolysis, fuel oil, alternative energy.

\begin{abstract}
Abstrak
Sampah kantong plastik di Indonesia sangat memprihatinkan. Banyaknya penggunaan kantong plastik dan yang terbuat dari plastik di sektor makanan, industri, dan lainnya yang akan berdampak buruk terhadap lingkungan jika dilakukan terus menerus dan pemanfaatan limbah kantong plastik tersebut. Penelitian ini dilakukan dengan memanfaatkan limbah kantong plastik untuk dikonversi menjadi bahan bakar minyak dengan proses pirolisis. Mulai dari perancangan dan pembuatan perangkat pirolisis, proses pirolisis untuk mengekstraksi bahan bakar minyak, dan pengujian laboratorium terhadap kepadatan minyak, viskositas minyak, dan nilai kalor minyak. Pirolisis dilakukan tiga kali dengan suhu pemanasan yang bervariasi pada $200^{\circ} \mathrm{C}, 250^{\circ} \mathrm{C}$, dan $300^{\circ} \mathrm{C}$. Penelitian ini menyimpulkan bahwa minyak pirolisis limbah kantong plastik jenis Low Density Polyetylene (LDPE) yang dapat dimanfaatkan untuk bahan bakar alternatif dalam penelitian ini dapat dinyalakan melalui percikan api pada suhu pemanasan $250^{\circ} \mathrm{C}$ dengan viskositas $1,95 \mathrm{cP}$, nilai kalor 10826,388 $\mathrm{kal} / \mathrm{gr}$, dan kepadatan minyak 0,7044 gr/ml.
\end{abstract}

Kata kunci: Plastik, pirolisis, bahan bakar minyak, energi alternatif.

\section{Pendahuluan}

Semakin berkembangnya teknologi yang diterapkan pada mesin kendaraan bermotor maupun industri, memungkinkan meningkatnya konsumsi bahan bakar minyak yang digunakan manusia setiap harinya. Peningkatan konsumsi bahan bakar minyak ini disebabkan juga karena bertambahnya populasi manusia dan ketergantungan penggunaan bahan bakar minyak yang sudah menjadi kebiasaan. Faktor-faktor tersebut akan menyebabkan kelangkaan bahan bakar minyak yang semakin menipis [1].

Keterbatasan sumber daya energi berbasis fosil dan dampak polusi udara, mendorong setiap negara di dunia mengembangkan energi alternatif dan 
energi baru terbarukan yang ramah lingkungan. Tidak terkecuali Indonesia. Indonesia merupakan salah satu negara dengan potensi energi baru dan terbarukan (EBT) yang sangat melimpah. Sayangnya sumber-sumber energi terbarukan tersebut belum dimanfaatkan secara maksimal. Berdasarkan data, 94\% energi di Indonesia masih menggunakan energi berbahan fosil (batubara, minyak bumi, dan gas alam) dan sisanya, 6\%, memanfaatkan sumber energi terbarukan. Energi terbarukan adalah sumber energi yang cepat dipulihkan kembali secara alami, dan prosesnya berkelanjutan. Konsep energi terbarukan mulai dikenal di dunia pada 1970-an [2].

Penemuan plastik ini, mempunyai dampak positif yang luar biasa, karena plastik memiliki keunggulan-keunggulan dibanding material lain. Tetapi di sisi lain, sampah plastik juga mempunyai dampak negatif yang cukup besar. Keunggulan plastik dibanding material lain diantaranya kuat, ringan, fleksibel, tahan karat, tidak mudah pecah, mudah diberi warna, mudah dibentuk, serta isolator panas dan listrik yang baik. Sedangkan plastik yang sudah menjadi sampah akan berdampak negatif terhadap lingkungan maupun kesehatan manusia [3].

Sampah plastik akan berdampak negatif terhadap lingkungan karena tidak dapat terurai dengan cepat dan dapat menurunkan kesuburan tanah. Sampah plastik yang dibuang sembarangan juga dapat menyumbat saluran drainase, selokan dan sungai sehingga bisa menyebabkan banjir. Pemusnahan sampah plastik dengan cara pembakaran (incineration), kurang efektif dan beresiko sebab dengan pembakaran munculnya polutan dari emisi gas buang (CO2, CO, NOx, dan SOx) dan beberapa partikulat pencemar lainnya sehingga diperlukan cara pengolahan lain untuk mengolah sampah plastik. Sampah plastik yang dibakar bisa mengeluarkan zatzat yang berbahaya bagi kesehatan manusia. Semakin meningkatnya sampah plastik ini akan menjadi masalah serius bila tidak dicari penyelesaiannya. Penanganan sampah plastik yang populer selama ini adalah dengan 3R (Reuse, Reduce, Recycle). Reuse adalah memakai berulang kali barang-barang yang terbuat dari plastik. Reduce adalah mengurangi pembelian atau penggunaan barang-barang dari plastik, terutama barangbarang yang sekali pakai. Recycle adalah mendaur ulang barang-barang yang terbuat dari plastik [3].

\section{Tinjauan Teoritis}

Penelitian lain yang berkaitan dengan pirolisis sampah plastik yaitu dipublikasikan [5] tentang pengolahan sampah secara pirolisis dengan variasi rasio komposisi sampah dan jenis plastik, dalam pengujian ini dapat disimpulkan bahwa salah satu jenis sampah plastik yang dapat menghasilkan gas tertinggi yaitu jenis plastik Polyethylene Terephthalene (PET) yaitu $45,40 \%$ dan salah satu jenis plastik yang menghasilkan wax tertinggi yaitu jenis plastik High Density Polyethylene (HDPE) sebesar 69,91\%. Reaktor pengujian mempunyai kapasitas 500 gram dan berbahan dari stainless steel.

Penelitian tentang karakteristik sifat fisik dan kimia minyak hasil pirolisis lambat campuran sampah kertas dan daun, dari pengujian yang sudah dilakukan diperoleh kesimpulan bahwa viskositas tertinggi minyak hasil pirolisis didapat pada komposisi $25 \%$ kertas, $75 \%$ daun dengan temperatur $350^{\circ} \mathrm{C}$ sebesar $65 \mathrm{~mm} 2 / \mathrm{s}$, dan nilai kalor terbesar didapatkan pad komposisi $25 \%$ daun, $75 \%$ kertas dengan temperatur $450^{\circ} \mathrm{C}$ yaitu sebesar 11,59 $\mathrm{MJ} / \mathrm{kg}$ [6].

Penelitian tentang pengolahan limbah kantong plastik jenis kresek menjadi bahan bakar menggunakan proses pirolisis, dalam pengujiannya didapat bahwa nilai kalor bahan bakar minyak hasil pirolisis yaitu sebesar $10.541,75 \mathrm{kkal} / \mathrm{kg}$ dari hasil perhitungan komposisi kimianya, dan titik nyala memenuhi standar mutu bahan bakar di Indonesia [7].

Minyak hasil pirolisis dari sampah plastik LDPE diperoleh sebanyak $525 \mathrm{ml}$ dari sampah plastik LDPE sebanyak $1 \mathrm{~kg}$ 
sedangkan pada minyak hasil pirolisis dari sampah plastik PET (Polyethylene Terephthalate) diperoleh sebanyak 368.47 $\mathrm{ml}$ dari sampah plastik PET sebanyak $1 \mathrm{~kg}$. Hasil pengujian kualitas bahan bakar minyak dari sampah plastik LDPE antara lain, nilai densitas dari sampah LDPE yaitu $0.7673 \mathrm{~kg} / \mathrm{L}$ mendekati nilai densitas dari minyak tanah dengan nilai range $0.78-0.81$ $\mathrm{kg} / \mathrm{L}$. Nilai viskositas dari sampah LDPE yaitu $0.7923 \mathrm{cP}$ termasuk ke dalam jenis minyak tanah dengan nilai pada tabel diantara range $0.294-3.34 \mathrm{cP}$ [3].

Penelitian tentang minyak pirolisis dari plastik polietilena, hasil penelitian menunjukkan bahwa minyak pirolisis dari plastik polietilena mempunyai densitas 939 $\mathrm{kg} / \mathrm{m} 3$ atau lebih berat dari minyak tanah. Minyak bakar ini mempunyai ignition point $30,4^{\circ} \mathrm{C}$ sehingga sangat mudah dinyalakan. Komponen utama minyak pirolisis dari plastik polietilena adalah styrene monomer yang kadarnya hampir 64\%. Sedangkan lebih dari $80 \%$ minyak pirolisis ini terdiri dari styrene [4].

Pirolisis merupakan suatu proses pemecahan struktur partikel kimia yang terdapat pada bahan dengan cara dipanaskan tanpa atau sedikit adanya oksigen didalam tabung reaktor, yang kemudian akan terjadi uap dan dikondensasi melalui pipa pendingin. Proses pirolisis terdapat dua jenis dalam satu proses pirolisis yaitu pirolisis primer dan pirolisis sekunder. Pirolisis primer adalah proses pirolisis dimana bahan dasar dipanaskan pada suhu dibawah $300^{\circ} \mathrm{C}$, yang akan diurai dan menghasilkan karbon atau arang. Pirolisis sekunder adalah proses pirolisis yang terjadi pada saat pirolisis primer selesai yaitu pada suhu di atas $600^{\circ} \mathrm{C}$, reaksi berupa gas atau uap dan menghasilkan karbonmonoksida (CO), hidrokarbon, dan hidrogen [8].

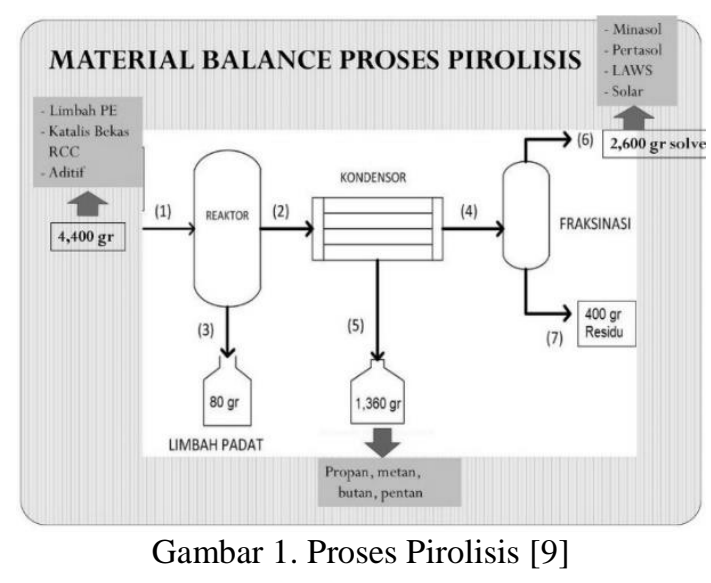

Plastik merupakan struktur polimer yang pada umumnya terdapat molekul molekul sederhana atau biasa disebut monomer yang mempunyai ikatan satu sama lain membentuk rantai panjang. Monomer terdiri atas molekul-molekul hidrogen dan karbon, tidak hanya hidrogen dan karbon tetapi monomer seperti propena $\left(\mathrm{C}_{3} \mathrm{H}_{6}\right)$, etena $\left(\mathrm{C}_{2} \mathrm{H}_{4}\right)$, vinil chlorida $\left(\mathrm{CH}_{2}\right)$, nylon, carbonat $\left(\mathrm{CO}_{3}\right)$, dan styrene $\left(\mathrm{C}_{8} \mathrm{H}_{8}\right)$ juga terdapat pada plastik termasuk jenis plastiknya.

Tabel 1. Jenis-jenis Polimer Plastik [10]

\begin{tabular}{|c|c|c|}
\hline No & Polimer & Penggunaan \\
\hline 1 & $\begin{array}{l}\text { PETE atau PET } \\
\text { (Polyethylene } \\
\text { Terephthalate) }\end{array}$ & $\begin{array}{l}\text { Botol plastik, botol } \\
\text { minyak sayur, tempat } \\
\text { makan ovenproof }\end{array}$ \\
\hline 2 & $\begin{array}{l}\text { HDPE (High } \\
\text { Density } \\
\text { Polyethylene) } \\
\end{array}$ & $\begin{array}{l}\text { Botol susu atau jus yang } \\
\text { berwarna putih, } \\
\text { kemasan mentega }\end{array}$ \\
\hline 3 & $\begin{array}{l}\text { V atau PVC } \\
\text { (Polyvinyil } \\
\text { Chloride) }\end{array}$ & $\begin{array}{l}\text { Botol deterjen atau } \\
\text { shampoo, pipa saluran }\end{array}$ \\
\hline 4 & $\begin{array}{l}\text { LDPE (Low } \\
\text { Density } \\
\text { Polyethylene) }\end{array}$ & $\begin{array}{l}\text { Kantong belanja, } \\
\text { pembungkus makanan } \\
\text { segar, botol yang dapat } \\
\text { ditekan }\end{array}$ \\
\hline 5 & $\begin{array}{c}\mathrm{PP} \\
\text { (Polypropylene) }\end{array}$ & $\begin{array}{l}\text { Pembungkus biscuit, } \\
\text { sedotan, botol minuman } \\
\text { atau obat }\end{array}$ \\
\hline 6 & $\begin{array}{c}\text { PS } \\
\text { (Polystyrene) }\end{array}$ & $\begin{array}{l}\text { Styrofoam, Wadah } \\
\text { makanan beku atau siap } \\
\text { saji }\end{array}$ \\
\hline
\end{tabular}

\section{Metode Penelitian}

Bahan-bahan yang digunakan dalam pembuatan minyak hasil pirolisis ini antara lain: stainless steel 300, dan besi, serta sampah kantong plastik jenis LDPE untuk bahan uji alat pirolisis. 
Peralatan yang digunakan pada penelitian ini adalah: viscometer brookfield, piknometer, kalorimeter, timbangan, stopwatch, thermometer, heater (alat pemanas) dan gelas ukur.

Membuat reaktor yang berbentuk tabung dengan besaran diameter $30 \mathrm{~cm}$ dan tinggi $35 \mathrm{~cm}$ menggunakan bahan stainless steel 300. Lubangi pada sisi samping tutup reaktor untuk tempat termometer dan lubangi juga pada sisi tengah tutup tabung reaktor untuk jalur pipa keluaran gas uap. Membuat alat pendingin atau kondensor berjumlah dua buah dengan bentuk tabung berdiameter $15 \mathrm{~cm}$ tinggi $20 \mathrm{~cm}$, dan tabung kedua dengan diameter $15 \mathrm{~cm}$ tinggi $15 \mathrm{~cm}$, kemudian lubangi pada setiap sisi samping kondensor untuk tempat pipa masuk dan keluar air pendingin dan lubangi pada sisi samping lain untuk tempat pipa masuk dari tabung reaktor.

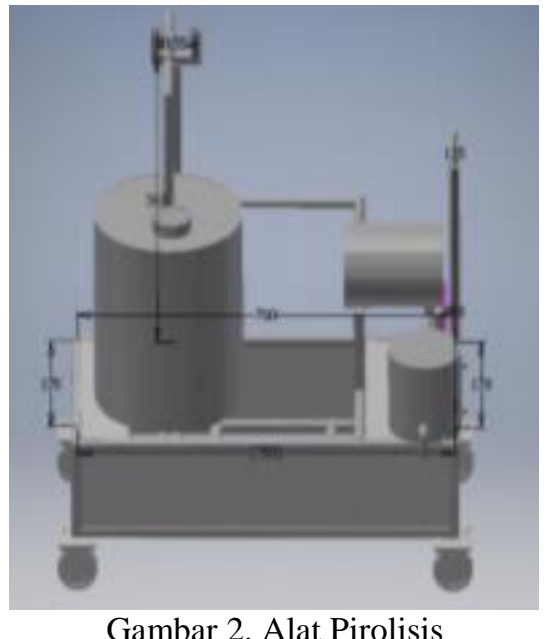

Gambar 2. Alat Pirolisis

Ada beberapa tahapan dalam melakukan proses pirolisis pada penelitian ini, diantaranya: Mengumpulkan bahan pirolisis sampah kantong plastik atau plastik kresek dengan warna campuran. Membersihkan sampah kantong plastik dari kotoran tanah maupun yang lain dan mengeringkannya jika kantong plastik terdapat air. Menimbang sampah kantong plastik sesuai sengan kapasitas reaktor (2 $\mathrm{kg}$ ). Memasukkan sampah kantong plastik yang sudah ditimbang ke dalam reaktor dengan memadatkannya. Menutup reaktor serapat mungkin supaya tidak terjadi kebocoran saat pirolisis berlangsung.
Menyalakan pemanas atau kompor bertekanan dengan suhu bervariasi yaitu suhu $200^{\circ} \mathrm{C}$, suhu $250^{\circ} \mathrm{C}$, dan suhu $300^{\circ} \mathrm{C}$ (melakukan 2 kali pengujian pirolisis dengan melakukan langkah yg sama), dijaga kestabilan suhu pada masing-masing pengujian.

Data hasil yang didapatkan dari laboratorium mengenai masa jenis, viscosity, dan nilai kalor dari minyak. Kemudian, data dianalisa dengan membandingkan data referensi yang sudah ada maupun data standar yang valid.

\section{Hasil dan Pembahasan}

1. Pengamatan Visual Minyak Pirolisis

Beberapa hal yang dilakukan dalam pengamatan visual pada minyak hasil pirolisis yaitu kejernihan dari minyak dan warna minyak.

\begin{tabular}{clll}
\multicolumn{3}{l}{ Tabel 2. Hasil pengamatan Visual } \\
\hline No & Sampel & Warna & Kejernihan \\
\hline 1 & T200 ${ }^{\circ} \mathrm{C}$ & $\begin{array}{l}\text { Kuning } \\
\text { keruh }\end{array}$ & Sedikit jernih \\
\hline 2 & T250 ${ }^{\circ} \mathrm{C}$ & $\begin{array}{l}\text { Kuning } \\
\text { bening }\end{array}$ & Jernih \\
\hline 3 & $\mathrm{~T}^{2} 00^{\circ} \mathrm{C}$ & $\begin{array}{l}\text { Sedikit } \\
\text { keruh }\end{array}$ & Kurang jernih \\
\hline
\end{tabular}

Keterangan: $\quad \mathrm{T} 200^{\circ} \mathrm{C} \quad($ Temperatur pemanasan $200^{\circ} \mathrm{C}$

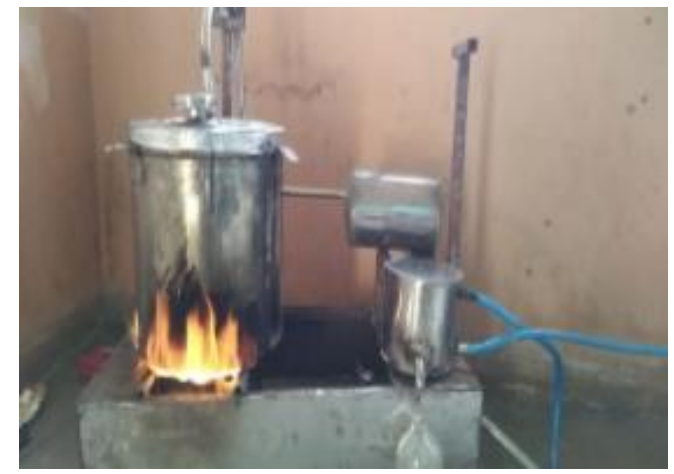

Gambar 3. Proses Pirolisis Limbah Sampah Plastik LDPE

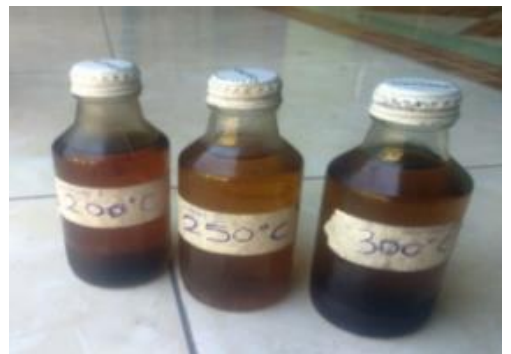

Gambar 4. Minyak Pirolisis Sampah Plastik LDPE 
2. Pengujian Kuantitas Minyak

Hasil pirolisis sampah plastik LDPE berdasarkan pada kuantitas input ditunjukkan pada Tabel 3.

Tabel 3. Kuantitas Minyak

\begin{tabular}{cccc}
\hline Sampel & $\begin{array}{c}\text { Suhu } \\
\text { pemanasan } \\
\left({ }^{\circ} \mathrm{C}\right)\end{array}$ & $\begin{array}{c}\text { Waktu } \\
(\text { jam })\end{array}$ & $\begin{array}{c}\text { Jumlah } \\
\text { minyak } \\
(\mathrm{ml})\end{array}$ \\
\hline $\mathrm{T} 200^{\circ} \mathrm{C}$ & 200 & 8 & 243 \\
\hline $\mathrm{T} 250^{\circ} \mathrm{C}$ & 250 & 7 & 625 \\
\hline $\mathrm{T} 300^{\circ} \mathrm{C}$ & 300 & 8 & 1172 \\
\hline
\end{tabular}

Faktor yang mempengaruhi jumlah keluaran minyak dan waktu yang diperlukan dalam satu proses pirolisis pada penelitian ini yaitu kestabilan suhu sangatlah berpengaruh dalam waktu dan jumlah pengeluaran minyak yang dihasilkan. Karena, dengan tidak stabilnya suhu pemanasan dalam proses pirolisis berlangsung akan mempengaruhi tekanan di dalam reaktor yang mengakibatkan tekanan juga tidak stabil sehingga pengeluaran minyak akan sangat minim

3. Pengujian Laboratorium Viskositas Minyak, Nilai Kalor Minyak, dan Berat Jenis Minyak

Pengujian laboratorium minyak hasil pirolisis sampah kantong plastik berjenis LDPE dengan 2 kali pengujian maka dapat dianalisa dan diketahui bahwa data hasil uji laboratorium minyak pirolisis seperti pada Tabel 4 dibawah ini:

Tabel 4. Nilai Rata-rata Pengujian Laboratorium Minyak Hasil Pirolisis

\begin{tabular}{cccc}
\hline \multirow{2}{*}{ Sampel } & \multicolumn{3}{c}{ Analisa } \\
\cline { 2 - 4 } & $\begin{array}{l}\text { Berat } \\
\text { Jenis } \\
(\mathrm{gr} / \mathrm{ml})\end{array}$ & $\begin{array}{c}\text { Viskositas } \\
(\mathrm{cP})\end{array}$ & $\begin{array}{c}\text { Nilai } \\
\text { Kalor } \\
(\mathrm{kal} / \mathrm{gr})\end{array}$ \\
\hline $\mathrm{T} 200^{\circ} \mathrm{C}$ & 0,7080 & 2,15 & 10481,96 \\
\hline $\mathrm{T} 250^{\circ} \mathrm{C}$ & 0,7044 & 1,95 & 10826,39 \\
\hline $\mathrm{T} 300^{\circ} \mathrm{C}$ & 0,7280 & 2,15 & 11276,21 \\
\hline
\end{tabular}

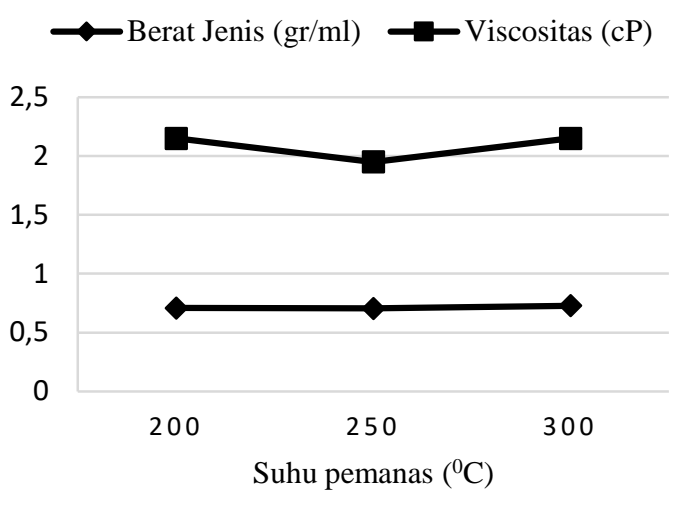

Gambar 5. Grafik Berat Jenis dan Viskositas Minyak

Nilai kalor minyak terendah terdapat pad sampel $\mathrm{T} 200^{\circ} \mathrm{C}$ sebesar $10481,959 \mathrm{kal} / \mathrm{gr}$ dengan suhu $200^{\circ} \mathrm{C}$ saat pengujian pirolisis sampah kantong plastik jenis LDPE. Data tersebut menunjukkan bahwa suhu yang digunakan dalam pirolisis berpengaruh terhadap nilai kalor minyak. Semakin naik suhu yang digunakan dalam pirolisis semakin naik pula nilai kalor minyak yang didapat (Gambar 6).

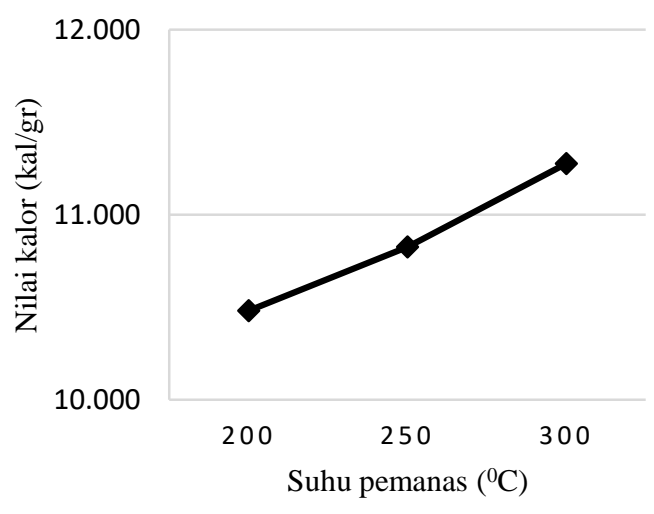

Gambar 6. Grafik Nilai Kalor Minyak

Hasil tersebut menunjukkan bahwa setiap kode sampel minyak masing-masing memiliki nilai yang berbeda pada setiap jenis pengujiannya. Hal itu disebabkan oleh beberapa faktor yang mempengaruhi, diantaranya suhu yang digunakan dalam proses pirolisis, kestabilan suhu harus dijaga, dan panjang jalur pipa gas.

\section{Kesimpulan}

Pada penelitian tentang Analisis karakteristik pirolisis limbah plastik LDPE sebagai bahan bakar alternatif dan 
pembuatan alat pirolisis sebagai media pengubah sampah kantong plastik menjadi bahan bakar minyak dan uji laboratorium minyak yang sudah dilakukan. Berdasarkan data hasil yang diperoleh dapat disimpulkan bahwa minyak hasil pirolisis sampah kantong plastik berjenis LDPE yang paling baik dalam penelitian ini yaitu pada suhu $250^{\circ} \mathrm{C}$, dengan viskositas sebesar $1,95 \mathrm{cP}$, nilai kalor sebesar 10826,388 kal/gr, dan massa jenis minyak sebesar $0,7044 \mathrm{gr} / \mathrm{ml}$. Minyak hasil pirolisis sampah kantong plastik LDPE dapat dinyalakan melalui percikan api dan dapat dijadikan sebagai sumber energi alternatif.

\section{Ucapan terimakasih}

Terima kasih diucapkan kepada Lembaga Penelitian, Publikasi dan Pengabdian Masyarakat Universitas Muhammadiyah Yogyakarta yang telah memberikan pendanaan dalam penelitian ini melalui hibah internal penelitian LP3M UMY.

\section{Referensi}

[1]. Sa'adah A. F., 2018. Peramalan Penyediaan dan Konsumsi Bahan Bakar Minyak Indonesia dengan Model Sistem Dinamik. Jurnal Ekonomi dan Pembangunan Indonesia. Volume 17, No. 2. 118137.

[2]. Retnowulan, D.A., Berbagai Energi Alternatif Yang Bisa Gantikan Fosil. Informasi dari https://www.suaramerdeka.com/smc etak/baca/204375/ (Diakses pada 1403-2020).

[3]. Iswadi D., et al., 2017. Pemanfaatan Sampah Plastik Ldpe Dan Pet Menjadi Bahan Bakar Minyak Dengan Proses Pirolisis. Jurnal Ilmiah Teknik Kimia, Universitas Pamulang. Banten. Vol. 1 No. 2.

[4]. Pranata, J. 2008. Pemanfaatan Sampah Kota Sebagai Bahan Bakar Pada Turbin Gas Yang Tidak Terpakai Di PT. Arun NGL
Menggunakan Proses Gasifikasi. Aceh

[5]. Rachmawati, Q., and Herumurti, W., 2015. Pengolahan Sampah Secara Pirolisis dengan Variasi Rasio Komposisi Sampah dan Jenis Plastik. Jurnal Teknik ITS, 4(1), D27-D29.

[6]. Suksewati, D. D., 2010. Karakteristik Sifat Fisik Dan Kimia Minyak Hasil Pirolisis Lambat Campuran Sampah Kertas dan Daun (Doctoral dissertation, Universitas Sebelas Maret).

[7]. Nasrun, N., et al., 2017. Pengolahan Limbah Kantong Plastik Jenis Kresek Menjadi Bahan Bakar Menggunakan Proses Pirolisis. Jurnal Energi Elektrik, 4(1).

[8]. Juliastuti, S.R., 2015. Pengolahan Limbah Plastik Kemasan Multilayer LDPE (Low Density Poly Ethilene) dengan Menggunakan Metode Pirolisis Microwave. Seminar Nasional Teknik Kimia Kejuangan.

[9]. Naimah S., et al., 2016. Konversi Limbah Plastik Polyethylene (PE) menjadi Solven Sebagai Substitusi Impor. Workshop Litbang BBKK.

[10]. [10] Bahraini, A.., 2019. 7 Tipe Plastik yang Perlu Anda Ketahui. Waste For Change. PT. Waste For Change Alam Indonesia. 